\title{
LEVANTAMENTO GEOFÍSICO NO "ABANICO EL PASO" COCHABAMBA-BOLÍVIA ${ }^{1}$
}

\author{
N.Ellert ${ }^{2}$, C.S.Rodas ${ }^{2}$, V.Ricaldi ${ }^{3}$, L.A.Jaldin ${ }^{3}$
}

PALAVRAS-CHAVE: Eletrorresistividade, água subterrânea e Geofisica Aplicada.

ELLERT, N. et al. (1994) Levantamento geofísico no "Abanico el Paso" Cochabamba-Bolívia. Bol.IGUSP. Sér.Cient,, 25:97-109.

\section{RESUMO}

$\mathrm{Na}$ bacia sedimentar de Cochabamba-Bolivia, localizada na provincia de mesmo nome, encontra-se situada a cidade de Cochabamba que utiliza grande volume de água subterrânea para seu abastecimento $\mathrm{c}$ irrigação da zona agricola. Trata-se de uma bacia intramontana limitada pelas Cordilheiras Ocidental e Oriental. Nos sopés da Cordilheira Ocidental encontram-se localizados vários leques aluvionares (abanicos) constituidos de material grosseiro, mesclado com material mais fino, representando importantes fontes de água subterrânea.

Um levantamento geofisico empregando a eletrorresistividade, em seu procedimento de sondagem elétrica vertical, foi executado com o objetivo de verificar a possibilidade de serem detectadas as presenças de palco-canais. Estes paleo-canais correspondem às melhores partes para a construçã̃o de poços profundos, dadas às altas permeabilidades e porosidades ai reinantes.

Para a aferição dos dados geofísicos, foram utilizados dados de poços perfurados no local, onde foram determinadas as porcentagens de cascalho areia e argila. Procurou-se estabelecer uma correlação entre a vazão especifica dos poços e seus teores de areia + cascalho.

Com dados de resistividade aparente das sondagens elétricas verticais, foram construidos gráficos de caminhamento elétrico, para diferentes espaçamentos $\mathrm{AB} / 2$ (como se diversos caminhamentos tivessem sido realizados com pontos de medida a cada ponto da sondagem elétrica vertical). Estes perfis mostram a distribuiçāo lateral da resistividade que pode ser correlacionada com a litologia e por conseguinte, com as possibilidades de determinar locais mais favoráveis à construção de poços profundos.

\section{ABSTRACT}

Vertical electrical soundings were measured in the Cochabamba sedimentary basin at several alluvial fans (locally called "abanicos"). This paper presents data from the Abanico El Paso. This research attempted to correlate geophysical data with the presence of paleo-channels inside the alluvial fans. These fans, mostly concentrated at the foot of the Cordilheira Ocidental, are about $1 \mathrm{~km}$ across and up to $4 \mathrm{~km}$ long. Data from deep wells were used to establish a correlation between the geophysical and hydrogeological data. The specific yield of the deep wells can be correlated with the grain size of the

\footnotetext{
'Estudo financiado pelo IDRC - International Development Research Centre - Projeto Centre File N.3-P-88-1059, 3-P-88-1029

${ }^{2}$ Departamento de Geologia Econômica e Geofisica Aplicada, Instituto de Geociências/USP, Sð̊o Paulo, Brasil.

${ }^{3}$ Pesquisadores CORDECO-Corporación para el Desarrollo de Cochabamba.
} 
sediments. Apparent resistivity values of the vertical electrical soundings, for several $A B / 2$ spacings were used to construct resistivity profiles, were the distance between each measured points corresponds to the distance between the points where a vertical electrical sounding was measured. Once again, the eletro-resitivity method demonstrated its potentiality as an exploration tool.

\section{INTRODUÇĀO}

Como parte das atividades a serem desenvolvidas pelo CEPAS-Centro de Pesquisas de Águas Subterrâneas do Instituto de Geociências da USP dentro do projeto financiado pelo IDRC-International Development Research Centre, estava prevista a execução de um levantamento geofisico em várias áreas dentro da Bacia de Cochabamba. Esta participação do CEPAS se fez através do apoio financeiro de dois projetos mantidos pelo IDRC, a saber: Centre Fíle N.3-P-881059 e 3-P-88-1029.

Dentro do escopo do projeto, foram investigadas várias áreas, localizadas em leques de piemonte (abanicos) situados dentro da bacia sedimentar de Cochabamba. Estes trabalhos tiveram a participação efetiva da CORDECO-Corporación para el Desarrollo de Cochabamba-Bolivia, na forma de: infraestrutura, pessoal, transporte, informações e apoio logistico. Nesta oportunidade foram também montadas equipes de pesquisa na CORDECO na forma de complementação com equipamento geofísico e treinamento de pessoal para execução dos trabalhos de campo e interpretação dos dados coletados.

\section{LOCALIZAÇĀO DA ÁREA PES- QUISADA. CONSIDERAÇŌES}

Cochabamba é a capital da província de mesmo nome, situada na parte central da Bolivia. Situa-se a meio caminho entre Santa Cruz de la Sierra e La Paz (Fig. 1). Trata-se de uma cidade construida em uma bacia sedimentar intramontana, com uma topografia relativamente plana a uma altitude ao redor dos $\mathbf{2} .600$ metros acima do nível do mar.

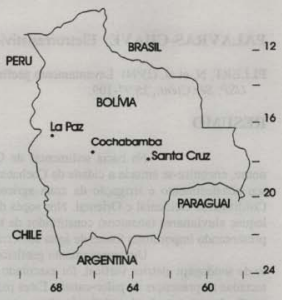

Figura 1 - Localizaçăo da área pesquisada.

Possui uma população ao redor de 300.000 habitantes, com uma economia fortemente apoiada na agricultura. Dentre os produtos agricolas destaca-se a produçẫo de trigo, milho, batata, hortaliças frutas e flores. Secundariamente destaca-se a atividade pecuária, com produção de leite e lã. Dentro da Bacia de Cochabamba existe uma série de leques de piemonte (abanicos) concentrados principalmente nos sopés da Cordilheira Ocidental. Dentre os muitos leques existentes, vários foram estudados, porém neste trabalho apresentamos somente os resultados obtidos na área do Abanico El Paso.

$\mathrm{O}$ clima, consequêencia da sua altitude e precipitação pluviométrica, é classificado como temperado semi-árido, com temperaturas médias entre 14 e 17 graus Celcius e com uma precipitação entre 400 e $600 \mathrm{~mm} / \mathrm{ano}$, concentrada 
nas estações invernais de novembro a março.

\section{OBJETIVOS DOS TRABALHOS}

Dadas as caracteristicas da Bacia de Cochabamba e seus potenciais quanto à água subterrânea, foram construidos muitos poços profundos, perfurados em sedimentos de origem aluvionar e de piemonte. Dados destes poços mostram grandes variaçōes quanto às suas produtividades. Estas variações representam reflexos da litologia existente nos locais da perfuração, bem como as suas localizações dentro do contexto estratigráfico-estrutural.

Durante os periodos de seca que a cidade de Cochabamba e arredores vêm enfrentando, aparecem sérios problemas, tanto para o abastecimento de água potável para a população, como para a irrigação das atividades agricolas.

Muitos poços existentes na bacia têm apresentado redução de vazão com correspondentes rebaixamentos dos niveis estático e dinâmico, chegando inclusive a extremos de se tornarem improdutivos. Jordan (1992) mostra que o fluxo artesiano diminuiu drasticamente a partir de 1986, e que em muitos lugares a surgência desapareceu. Este fenômeno é fruto de uma superexplotação dos aqǘferos principais e uma redução da recarga devido aos periodos de seca. Verifica-se que a flutuação dos niveis na zona dos leques está diretamente influenciada pela presença de chuvas, pelo fornecimento de água pelos rios e pequenos arroios que descem da cordilheira.

Verificou-se que poços perfurados ao longo de páleo-canais associados aos leques (abanicos) apresentam granulometria mais grosseira, conseqüentemente apresentando vazões específicas mais elevadas.

Trabalhos anteriores (José \& Ellert, 1988) mostram que existe uma correlação entre dados geofísicos de eletrorresistividade e hidrodinâmicos. Neste sentido, este trabalho foi realizado com o objetivo de, a partir de dados obtidos por levantamentos de eletrorresistividade, identificar-se páleo-canais presentes dentro dos leques (abanicos), para posterior locação e perfuração de novos poços profundos. Com base nestes dados geofisicos, pretende-se definir a localização, profundidade e extensão dos paleo-canais, representados pela presença de materiais grosseiros (cascalhos) isentos ou pobres em material de granulação mais fina (argilas).

\section{CONSIDERAÇ̃̃ES GEOLÓGICAS E HIDROGEOQUÍMICAS}

O embasamento da bacia sedimentar é constituido por rochas do Paleozóico (Ordoviciano e Siluriano), bem como do Mesozóico (Cretáceo) e rochas Cenozóicas sedimentares do Terciário e Quaternário. Os sedimentos do embasamento cristalino representam litologias de pouco interesse para fins hidrogeológicos, sendo toda atenção voltada para os sedimentos Cenozóicos.

Rochas do terciário, representadas pela Formação Morochata, afloram a oeste da cidade de Cochabamba e repousam discordantemente sobre as rochas Cretáceas. Litologicamente constituída de rochas clásticas grosseiras com intercalações argilosas.

As rochas do Quaternário estão localizadas dentro de depressōes formadas durante os movimentos epirogenêni$\cos$ andinos. Nestas depressões aparecem sedimentos lacustres e leques aluvionais com enorme variedade litológica e granulométrica, conforme Figura 2.

O tamanho dos componentes dos sedimentos diminui progressivamente à medida que se avança rumo ao centro da bacia. A definição dos limites entre os sedimentos lacustres e aluviais é bastante dificil devido à mistura entre eles. Nas 

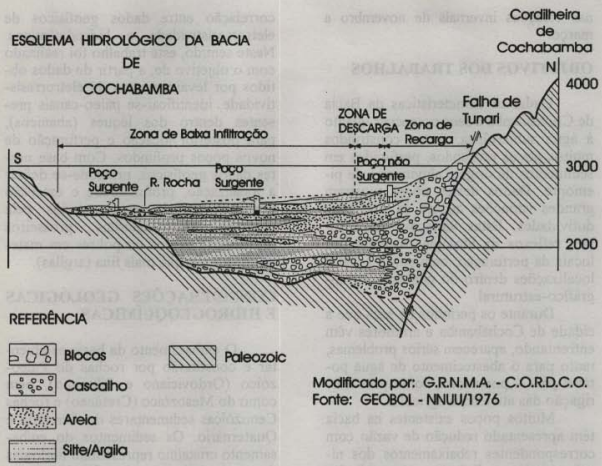

Modificado por: G.R.N.M.A. - C.O.R.D.C.O.

Fonte: GEOBOL - NNUU/1976

Figura 2 - Secão esquemática da Bacia de Cochabamba.

áreas da bacia onde não existe fornecimento de sedimentos grosseiros, a espessura destes sedimentos lacustres finos pode atingir até $1000 \mathrm{~m}$, segundo trabalhos geofísicos anteriores. Poços perfurados evidenciam uma grande heterogeneidade vertical e horizontal nos sedimentos, devido ao complicado sistema de leques aluvionais, e aos deltas lacustres, onde a sedimentação é ora ritmica, ora caótica. A interdigitação dos leques aluvionais, juntamente com a mudança dos leitos dos rios, faz com que estes depósitos dificilmente se relacionem. Este processo de interdigitação favorece às vezes o aparecimento de aquiferos confinados. Normalmente, abaixo dos $150 \mathrm{~m}$ de profundidade encontram-se depósitos argilosos, com pequenos leitos de cascalho e areia.
Quanto ao aspecto hidroquímico, em trabalhos anteriores da GEOBOL (Serviço Geológico da Bolivia)- Nações Unidas em 1978, verifica-se que na zona de leques (área de interesse dos trabalhos) e depósitos aluviais são encontradas águas subterrâneas que apresentam a mais baixa concentração iônica dentro da bacia, com condutividade elétrica entre 200 e 400 micromhos/cm e pH entre 7 e 8 . Os principais cátions são $\mathrm{Ca}^{++} \mathrm{e} \mathrm{Mg}^{++}$, enquanto os ânions principais são $\mathrm{Cl}^{-}$e $\mathrm{HCO}_{3}{ }^{-}$. Além deste seu conteúdo de sais, apresenta-se também rica em ions de $\mathrm{Fe}^{++}$. Já na faixa de transição a concentração salina se eleva, onde a água do aquifero livre chega a apresentar uma condutividade elétrica de até 1.500 micromhos $/ \mathrm{cm}$. O cátion principal passa a ser $0 \mathrm{Mg}^{++}$, presente a 
partir dos dolomitos do Cretáceo. $\mathrm{Na}$ faixa correspondente aos depósitos lacustres, a concentração salina é mais alta, em geral, com condutividade elétrica entre 400 e 1.500 micromhos/cm. O cátion mais comum é $\mathrm{Na}^{+}$e os ânions $\mathrm{Cl}^{-} \mathrm{HCO}_{3}^{-}$.

\section{DADOS DOS POÇOS PERFURA- DOS}

$\mathrm{Na}$ área especifica de El Paso (Fig. 3) existem vários poços perfurados, porém dadas as qualidades descritivas, serão apresentados os perfís resumidos de 6 poços, a saber P-14, P-14A, P-15, P-16, P-30 e P-33, poços perfurados por GEOBOL/USAID.

\section{Poço P-14}

Conforme mapa da Figura 3, este poço encontra-se mais afastado do sopé da cordilheira (representada por rochas do Paleozóico), no prolongamento do Abanico, próximo ao Rio Tacata. Possui uma profundidade total de 60 metros. Verifica-se que contém cerca de $29 \%$ de argila, $23 \%$ de areia e $48 \%$ de cascalho. De acordo com o teste apresenta uma vazão de $14,4 \mathrm{~m}^{3} / \mathrm{h}$ (Fig. 4).

\section{Poço P-14A}

Este poço, perfurado ao longo do Perfil I de geofisica, portanto mais a montante com relação ao centro da bacia, apresenta uma distribuição de $38 \%$ de argila, $31 \%$ de areia e $31 \%$ de casca-

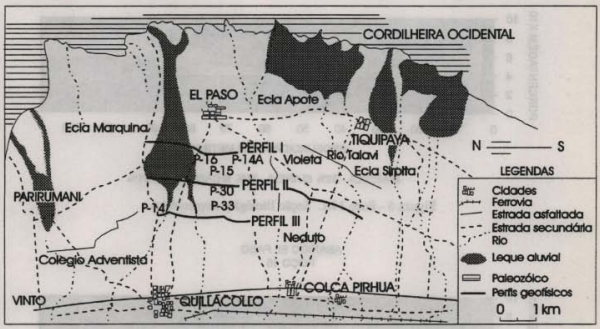

Figura 3 - Localizaçâo esquemática dos poços e perfís geofísicos.

Iho. Atingiu a profundidade de 118 metros, e apresenta uma vazão específica de $10,54 \mathrm{~m}^{3} / \mathrm{h} / \mathrm{m}$ (Fig. 5).

\section{Poço P-15}

Também perfurado ao longo do Perfil I de geofisica, entre os poços P$14 \mathrm{~A}$ e $\mathrm{P}-16$, possui uma profundidade de 120 metros. Apresenta $19 \%$ de argi- la, $36 \%$ de areia e $45 \%$ de cascalho. Seu teste de vazão indica uma vazão específica de $19,4 \mathrm{~m}^{3} / \mathrm{h} / \mathrm{m}$ (Fig. 6).

\section{Poço P-16}

Perfurado nas proximidades do poço P-15, apresenta uma profundidade de 120 metros, onde as argilas estão presentes na proporção de $35 \%$, as arei- 


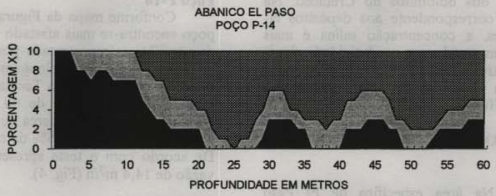

EARGILA - $29 \%$ IAREIA - $23 \%$ ECASCALHO - $48 \%$

Figura 4 - Perfil litológico esquemático.

ABANICO EL PASO

POÇO 14A

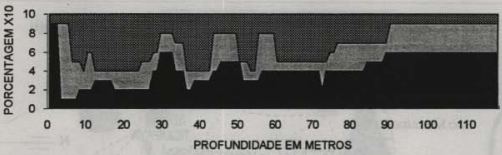

EARGILA - 38\% DAREIA - 31\% E CASCALHO - $31 \%$

Figura 5 - Poço 14A. Seção litológica esquemática.

\section{ABANICO EL PASO}

POÇO 15

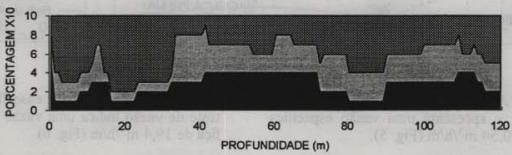

DARGILA - $19 \%$ DAREIA - 36\% ECASCALHO - $45 \%$

Figura 6 - Poço P-15. Seção litológica esquemática. 
as com $36 \%$ e os cascalhos com $29 \%$. Seu teste de vazão apresenta uma vazão especifica de $15 \mathrm{~m}^{3} / \mathrm{h} / \mathrm{m}$ (Fig. 7).

\section{Poço P-30}

Este poço, construido mais para o centro da bacia, possuiu uma profundidade de 60 metros. Interessante notar que nesta perfuração foram encontrados sedimentos pobres em areia, com as seguintes proporções: $37 \%$ de argila, $16 \%$ de areia e $49 \%$ de cascalho. A vazão específica indica uma produção de 12 $\mathrm{m}^{3} / \mathrm{h} / \mathrm{m}$ (Fig. 8).

\section{Poço P-33}

Perfurado em local mais próximo do centro da bacia, igualmente com profundidade de 60 metros. Os dados da perfuração revelam a presença de um elevado teor em argila, de $49 \%$, seguindo-se de areias $23 \%$ e cascalho $27 \%$. Também neste local a vazão especifica é baixa, de $1,2 \mathrm{~m}^{3} / \mathrm{h} / \mathrm{m}$ (Fig. 9).

Mesmo sendo um número pequeno de poços, aparentemente parece existir uma correlação entre a soma das porcentagens de areia e de cascalho e a vazão específica dos poços, conforme Figura 10. Considerando-se o comportamento relativamente linear da relação entre a soma de porcentagens de areia e de cascalho e a vazão específica, é de se esperar que um poço isento de argila apresente uma vazão especifica de 25 $\mathrm{m}^{3} / \mathrm{h} / \mathrm{m}$.

\section{LEVANTAMENTO GEOFISICO}

Considerando-se a aplicabilidade dos métodos elétricos, notadamente a sondagem elétrica vertical, os trabalhos de campo foram executados empregando-se esta metodologia, neste procedimento, utilizando-se o arranjo Schlumberger.

\section{Planejamento dos trabalhos}

$\mathrm{Na}$ região de El Paso existem perfurados vários poços profundos, dos quais os acima mencionados são os que apresentam uma melhor descrição, bem como apresentam vazões de testes e vazões especificas calculadas.

No sentido de procurar correlacionar os dados geofisicos com dados de vazão, bem como procurar detectar variações laterais na resistividade das camadas de modo que pudessem estar associadas às variações litológicas (notadamente quanto à granulometria), foram definidos 3 perfis. Estes perfis são aproximadamente paralelos ao sopé da cordilheira, cortando o leque aluvial, com extensão de 3.000 metros cada um, espaçados cerca de $1.200 \mathrm{~m}$, nos quais foram executadas 90 sondagens elétricas verticais, separadas de 100 metros entre si.

\section{Equipamento utilizado}

Para a execução dos trabalhos de campo foi utilizado um equipamento constando de uma fonte DC-DC, alimentada por bateria de $12 \mathrm{~V}$, com saida até $1.000 \mathrm{~V}$ e $500 \mathrm{~mA}$ de corrente. Para as medidas de diferença de potencial, bem como das correntes geradas pela fonte, foram utilizados multimetros digitais marca FLUKE, com elevada impedância de entrada e sensibilidade de 0,1 $\mathrm{mV}$ e $1 \mathrm{~mA}$, respectivamente.

Os eletrodos de corrente consistiam de hastes de aço inox, com diâmetro de $3 / 4$ de polegada e 1,20 metro de comprimento. Os eletrodos de potencial, manufaturados no CEPAS, consistiam de eletrodos não polariáveis $\mathrm{Cu} / \mathrm{CuSO}_{4}$, construidos com tubos de PCV rigido de $1 / 2$ polegada de diâmetro e comprimento de 1,30 metro. A extremidade porosa é constituída de uma ponta de madeira porosa mole, através da qual a solução de sulfato de cobre faz contato com o solo. Estes eletrodos assim construídos, rústicos no seu aspecto, revelaram-se altamente resistentes nos trabalhos de campo, tendo em momento algum apresentado qualquer problema. 


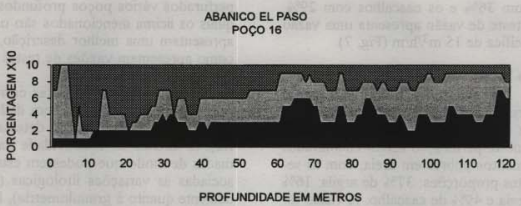

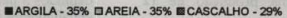

Figura 7 - Poço P-16. Seç̃o litológica esquemática.

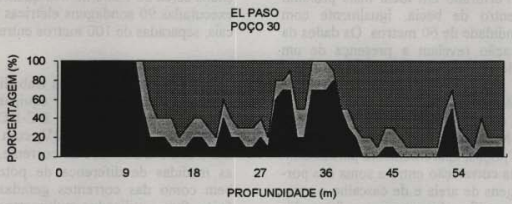

EARGILA - 37\% DAREIA - $16 \%$ E CASCALHO - $49 \%$

Figura 8 - Poço P-30. Seção litológica esquemática.

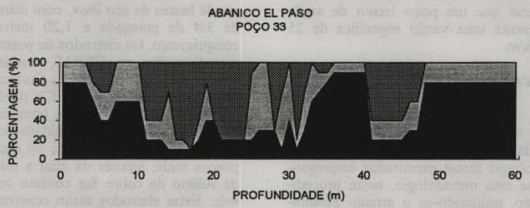

EARGILA - $49 \%$ 口AREIA - $23 \%$ 중 CASCALHO - $27 \%$

Figura 9 - Poço 33. Perfil litológico esquemático. 
RELAÇÃO VAZÃO X \%AREIA +\% CASCALHO

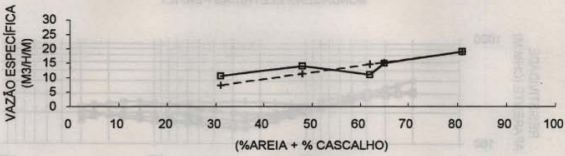

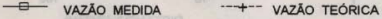

Figura 10 - Relação vazâo/soma das porcentagens de areia e cascalho.

A regiāo apresentou-se praticamente isenta de correntes telúricas, conferindo aos multimetros uma estabilidade muito grande, facilitando os trabalhos de campo.

De modo a reduzir a resistência de contato, procurou-se sempre instalar os eletrodos de corrente em locais que apresentavam solo pouco arenoso, sendo este sempre umedecido com água salgada.

\section{Dados obtidos}

Considerando-se o grande número de dados obtidos, bem como a diversidade dos tipos de curvas, apresentamos somente algumas curvas típicas obtidas (Fig. 11).

A grande vantagem de se executar sondagens elétricas verticais espaçadas por distâncias constantes e não muito grandes, é que permitem obter informações bastante importantes. De um lado, a partir da interpretação das curvas de sondagem elétrica vertical, é possivel determinar-se a "estratigrafia geoelétrica" da área pesquisada, onde os estratos com diferentes valores de resistividade são identificados, permitindo uma correlação entre camadas. Por outro lado, tomando-se o valor de resistividade aparente para diferentes espaçamen- tos de $\mathrm{AB} / 2$ de diferentes sondagens elétricas verticais, é possível construir-se perfis de caminhamento elétrico. Estes perfis serão tanto mais completos, quanto mais valores de espaçamentos $\mathrm{AB} / 2$ das curvas forem tomados. Para fins de representação dos dados da área pesquisada, são apresentados 6 espaçamentos $\mathrm{AB} / 2$ distintos a saber: $10 \mathrm{~m}, 20 \mathrm{~m}, 40 \mathrm{~m}$, $80 \mathrm{~m}, 160 \mathrm{~m}$ e $300 \mathrm{~m}$.

O Perfil I, Figura 12, com extensão de 3.000 metros foi obtido a partir de dados das sondagens elétricas verticais medidas mais próximas da cordilheira.

Verifica-se que em sua parte inicial os valores de resistividade são bastante semelhantes havendo pouca separação entre os valores encontrados. À medida que se desloca para a parte final do perfil, nota-se que os valores de resistividade aparente a diferentes profundidades vão se tornando gradativamente distintos, mostrando uma significativa estratificacão das camadas com granulometrias bastante variadas. Aos altos valores de resistividade devem estar associadas zonas de sedimentos mais grosseiras. Nota-se outrossim que a profundidades maiores, os valores de resistividade são mais baixos, reflexos de um aumento no conteúdo das argilas, 


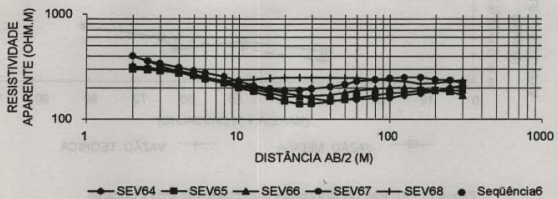

Figura 11 - Algumas curvas de SEV tipicas obtidas em El Paso.

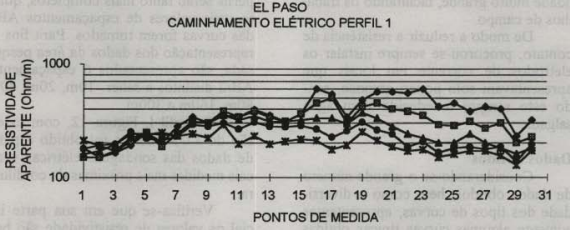

$\rightarrow A B / 2=20 M \rightarrow-A B / 2=40 M \rightarrow-A B / 2=80 M \rightarrow-A B / 2=160 M \rightarrow-A B / 2=300 M$

Figura 12 - Caminhamento elétrico Perfil 1.

ou então maior salinidade das águas mais profundas. Observando-se os perfis esquemáticos dos poços P-14A, P-15 e $\mathrm{P}-16$ construídos nas proximidades deste perfil, verifica-se que na parte inicial do perfil, o poço $\mathrm{P}-14 \mathrm{~A}$ apresenta uma porcentagem elevada de argila, crescente à medida que a profundidade aumenta, razão pela qual os valores de resistividade são baixos e mais uniformes. Já o poço $\mathrm{P}-16$, situado mais distante do inicio do perfil, apresenta uma menor concentra- ção de argila, com um crescente aumento no teor de areia à medida que a profundidade aumenta, razão pela qual se manifesta aquela separação entre as resistividades aparentes com o aumento do espaçamento $A B / 2$.

O Perfil II, Figura 13, é composto pelos valores de resistividade aparente encontrados nas sondagens elétricas medidas mais próximas do fim do "abaninico". Verifica-se que os valores de resistividade apresentam uma variabilidade 


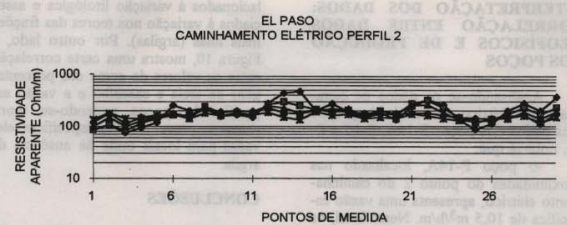

$$
\rightarrow A B / 2=20 \rightarrow-A B / 2=40 \rightarrow A B / 2=80 \rightarrow A B / 2=160 \rightarrow-A B / 2=300
$$

Figura 13 - Caminhamento elétrico Perfil II.

bastante inferior aos do Perfil I. Não obstante esta maior homogeneidade, há alguns pontos como as estações 13 e 12, bem como a 22 , onde aparecem grandes diferenças entre os valores de resistividade, reflexo de variações na litologia, como reflexo das granulometrias dos materiais aí presentes.

O Perfil III, Figura, 14, corresponde aos valores de resistividade de sondagens elétricas verticais localizadas mais próximas do centro da bacia sedimentar. Verifica-se uma maior homoge- neidade nos valores para uma mesma sondagem elétrica e uma maior constância em sua distribuição ao longo do perfil. Isto é fruto de uma maior homogeneidade dos materiais, mesmo a profundidades maiores. $\mathrm{O}$ poço $\mathrm{P}-33$ revela uma concentração elevada de argila, com pouca participação de areia e cascalho, havendo uma distribuição mais homogênea das fraçōes granulométricas, conferindo às sondagens elétricas verticais, uma menor distribuição de valores de resistividade aparente.

EL PASO

CAMINHAMENTO ELÉTRICO PERFIL 3

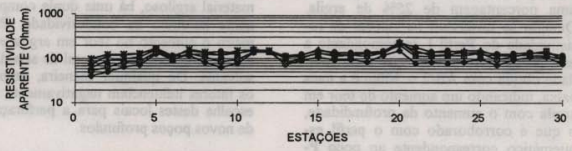

$\rightarrow A B / 2=20 \rightarrow-A B / 2=40 \rightarrow A B / 2=80 \rightarrow-A B / 2=160 \rightarrow-A B / 2=300$

Figura 14 - Caminhamento elétrico Perfil III. 


\section{INTERPRETACCÃO DOS DADOS: CORRELACÃo ENTRE DADOS GEOFÍSICOS E DE PRODUÇÃO DOS POCOS}

Analisando-se os dados de caminhamento elétrico, sobretudo do perfil I e os dados dos poços P-14A, P-15 e P16, nota-se que:

-o poço P-14A, localizado nas proximidades do ponto 2 do caminhamento elétrico, apresenta uma vazão especifica de $10,5 \mathrm{~m}^{3} / \mathrm{h} / \mathrm{m}$. Neste local, os valores de resistividade aparente se encontram distribuídos entre um mínimo de $150 \mathrm{Ohm}$.m para o ponto $\mathrm{AB} / 2=20 \mathrm{~m}$, e a partir dai, os valores crescem até um máximo de 190 Ohm.m para $\mathrm{AB} / 2=$ $160 \mathrm{~m}$, o que demonstra a presença de camadas grosseiras em profundidades maiores

-o poço $\mathrm{P}-15$, perfurado nas proximidades do ponto 5 do caminhamento elétrico apresenta vazão específica de 19 $\mathrm{m}^{3} / \mathrm{h} / \mathrm{m}$. Os valores de resistividade são mais elevados variando entre um mínimo de $185 \mathrm{Ohm} . \mathrm{m}$ para $\mathrm{AB} / 2=20 \mathrm{~m}$ e um máximo de 248 Ohm.m para $\mathrm{AB} / 2=$ $300 \mathrm{~m}$. Estes valores mais elevados indicam maior pobreza em argila (19\%) que se reflete também na maior vazão especifica.

-o poço P-16, perfurado nas proximidades do ponto 9 , mostra uma vazão especifica de $15 \mathrm{~m}^{3} / \mathrm{h} / \mathrm{m}$. Apresenta uma porcentagem de $25 \%$ de argila. Quando se observam os valores de resistividade do Perfil I correspondente a esta posição, verifica-se que a resistividade obtida com $\mathrm{AB} / 2=300 \mathrm{~m}$ é a mais baixa, indicando um aumento do teor em argila com o aumento da profundidade, o que é corroborado com o perfil esquemático correspondente ao poço P16.

De modo geral há uma boa correlação entre os dados geofisicos e os dados de vazão específica. Os dados de resistividade aparente podem ser corre- lacionados à variação litológica e associados à variação nos teores das fraçōes mais finas (argilas). Por outro lado, a Figura 10, mostra uma certa correlação entre os valores da soma das porcentagens de areia e cascalho e a vazão específica dos poços, podendo-se, teoricamente, prever vazốes específicas elevadas para locais onde há ausência de argila.

\section{CONCLUSÕES}

Os levantamentos geofisicos realizados em Cochabamba, no "Abanico El Paso" em particular, demonstram a aplicabilidade de métodos elétricos na definição de porçôes com litologias mais ou menos ricas em material fino argiloso, representando em importante elemento na definição de novos sitios para a perfuração de poços profundos. No caso particular os valores de resistividade estão associados à granulometria e menos influenciados pela composição quimica das águas subterrâneas, considerando-se que esta faixa investigada se encontra próxima da área de recarga (águas advindas das precipitações nas partes mais elevadas da cordilheira que descem pelas encostas e se infiltram nos sopés) onde as águas subterrâneas apresentam pobreza na quantidade de sais dissolvidos. Mais para o centro da bacia, onde ocorrem maiores concentrações de material argiloso, há uma dupla componente influindo na condutividade. Primeiro o aumento no teor em argila e o segundo, 0 aumento do total de sais dissolvidos. De qualquer maneira, ambos os fatores influenciam negativamente na escolha destes locais para a perfuração de novos poços profundos.

\section{REFERÊNCIAS BIBLIOGRÁFICAS}

GEOBOLNACIONES UNIDAS,

(1978) Investigaciones de Aguas Subterráneas en las Cuencas de Co- 
chabamba. Cochabamba, 250p. (Informe Técnico).

JORDAN, L.D. (1992) Sobre-explotación y processos de contaminación en los acuiferos de la Cuenca de Cochabamba por efectos de sequia. In: Seminario Nacional sobre Recursos Hidricos y Medio Ambiente. Cocha- bamba, 1992. Anales. Cochabamba. p.117-135.

JOSE, C.; ELLERT, N. (1988) Levantamento geofísico na Bacia do Alto Rio Turvo, SP. Correlação entre dados hidrodinâmicos e geoelétricos. Boletim IG-USP. Série Cientifica, v. 19 p. 87-110.

N.Ellert - Instituto de Geociências, Universidade de São Paulo, Caixa Postal 11.348, CEP 05422-970, São Paulo, SP, Brasil. 